\title{
¿EXISTE UN DIALECTO “ECUATOGUINEANO” DEL ESPAÑOL?
}

\author{
POR \\ JOHN M. LIPSKI \\ The Pennsylvania State University
}

\section{INTRODUCCIÓN}

Hoy día se estima en unos 400 millones el número de hablantes nativos o casi nativos de la lengua española en todo el mundo. El español es la lengua oficial en veinte y una naciones, en Europa, América y África. Fue lengua oficial hasta hace poco en Filipinas, es lengua co-oficial de la minúscula república de Andorra y la primera lengua de facto de la colonia británica de Gibraltar, sin mencionar los más de treinta y ocho millones de hablantes nativos del español en los Estados Unidos. En amplias regiones del mundo hispanoparlante hay grandes comunidades de habla en las cuales el español es una segunda lengua, a veces sólo parcialmente adquirida: podemos citar los sectores indígenas de México, Guatemala, Paraguay, Ecuador, Perú y Bolivia. A la par de las comunidades hispanoparlantes existe una amplia gama de tratados dialectológicos, que remontan hasta comienzos del siglo xx y que ofrecen descripciones minuciosas de casi todas las variedades del español en el mundo. En medio de todas las variantes dialectales del español estudiadas por más de un siglo, sobresale un caso curioso, el único lugar del mundo hispanoparlante donde se ha cuestionado repetidamente la existencia de un dialecto legítimo del español. Se trata de Guinea Ecuatorial, único país del África subsahariana de habla española.

La insólita condición de Guinea Ecuatorial dentro del marco de los estudios dialectológicos motiva la formación de dos interrogantes: (1) ¿Existe en realidad una variedad legítimamente ecuatoguineana del español? (2) En caso de una respuesta afirmativa, ¿a qué se debe la insistentenegación de su existencia? En los siguientes párrafos intentaremos responder a estas preguntas, de la siguiente forma. Demostraremos que es viable el concepto de una variedad guineana del español, de perfil sociolingüístico especial debido a su trayectoria histórica en tierras africanas. Al mismo tiempo atribuiremos al racismo multisecular, así como a las nefastas actitudes coloniales el poco reconocimiento del español guineano dentro de la hispanofonía mundial. 
ACTITUDES HACIA EL ESPAÑOL HABLADO POR LOS NEGROS:

ESPAÑA, AMÉRICA Y POR FIN ÁFRICA

A partir del siglo xv, las exploraciones portuguesas a lo largo de la costa occidental de África dieron lugar a la importación de africanos negros a Portugal, originalmente en condición de esclavos. Posteriormente, llegó a formarse una significativa población de color en Lisboa y sus alrededores, tanto de esclavos como de negros libres. Al ganar ímpetu la trata negrera portuguesa, España comenzó la compra de negros a Portugal, reemplazando paulatinamente a los moros del norte del África, como obreros, empleados domésticos y en otras áreas de trabajo forzado; las áreas españolas más caracterizadas por las poblaciones negras eran Sevilla, Huelva y Cádiz, y los territorios adyacentes, pero también se formaban núcleos poblacionales africanos en Madrid, Barcelona y aun en Galicia y el País Vasco. Como consecuencia lógica de la trata portuguesa, la figura del esclavo negro surge en la literatura portuguesa hacia mediados del siglo xV, casi siempre como bufón o "simple". El lenguaje deformado y grotesco de los personajes negros indica, además de la reducción natural que habría de producirse entre adultos de origen africano que se veían forzados a aprender el portugués bajo condiciones desfavorables, la formación incipiente de un criollo estable, que a largo plazo se convertiría en los dialectos afrolusitanos de Cabo Verde, Guinea-Bissau, Annobón y São Tomé. Poco después, la figura del negro bozal aparece en el teatro español, y para fines del siglo XVI el personaje literario del bozal era un componente establecido de las obras dramáticas del Siglo de Oro (Lipski, A History).

A juzgar por los documentos literarios, los españoles blancos pensaban que todos los negros hablaban un castellano defectuoso, sin basarse en experiencia propia, y al encontrarse con negros (o, en el caso de los escritores, al crear personajes negros), “oían” rasgos bozales aun cuando no existían en realidad. Es evidente que en España a partir del Siglo de Oro era más frecuente la burla racista y la parodia que el verdadero conocimiento del lenguaje de los africanos y sus descendientes. Abundan los estereotipos y las exageraciones, ejemplificado por la bien conocida afirmación de Quevedo de que "sabrás guineo en volviendo las rr 1l, y al contrario: como Francisco, Flancico; primo, plimo" (Quevedo 127). Las parodias literarias también incluyen burdos juegos de palabras (p. ej. el uso omnipresente de cagayera por caballero) y argumentos inverosímiles en que los africanos no hacen sino bailar, tocar el tambor, evitar el trabajo, y emperifollarse a la manera europea. Este lenguaje burlesco aun se usaba en ámbitos eclesiásticos, al ser incorporado a los muchos villancicos conocidos como negrillos que se cantaban en las iglesias y catedrales de España e Hispanoamérica, sobre todo en época de Navidad.

Este mismo estereotipo racista caracteriza casi toda la literatura negrista hispanoamericana, y refleja la opinión pública actual en algunas zonas. Estos comentarios provienen no sólo de los países caribeños, sino también de otras naciones cuyas poblaciones negras no son tan conocidas, y aún encontramos tales afirmaciones

Revista Iberoamericana, Vol. LXXX, Núms. 248-249, Julio-Diciembre 2014, 865-882 
entre investigadores académicos aparentemente libres de prejuicio racial. En Cuba, el sacerdote Nicolás Duque de Estrada redactó, en 1797, un pequeño catecismo o manual de instrucción para los clérigos que atendían a los esclavos cubanos. El autor describe el habla bozal como "aquel lenguaje de q. usan ellos sin casos, sin tpos., sin conjunciones, sin concordancias, sin orden [...]" (Laviña 67). Unos años después, en la segunda edición de su Diccionario provisional casi-razonado de vozes cubanas (1849), el lexicógrafo cubano Esteban Pichardo describía el lenguaje bozal:

[...] es un Castellano desfigurado, chapurrado, sin concordancia, número, declinación ni conjugación [...] una jerga más confusa mientras más reciente la inmigración; pero que se deja entender de cualquiera Español fuera de algunas palabras comunes a todos, que necesitan de traducción. (Pichardo, iv-v)

En 1861, el viajero norteamericano Hassaurek, al visitar la comunidad negra del Chota en la sierra ecuatoriana -donde el castellano ya se hablaba como única lengua nativa- quedó maravillado ante sus canciones festivas: "I was unable to make out any of the verses, but my companions told me the songs were composed by the Negroes themselves, and in their own dialect. Like the Negroes of the United States, the Negroes of Spanish America have a dialect and pronunciation of their own. The same guttural voices and almost unintelligible pronunciation, the same queer gesticulation and shaking of the body, the same shrewd simplicity and good humor [...]" (194). Casi un siglo después el personaje del negro figuraba en las comedias radiofónicas en la Cuba prerevolucionaria. Un artista negro, Amador Domínguez, aspiraba a una carrera intelectual, e intentaba alejarse del obligatorio papel del negro bufón que representaba en el teatro radiofónico; sus esfuerzos de superación personal le merecieron este comentario de parte del jefe de la emisora: “ ¡Bah! El día que aprendas a hablar como blanco no te van a llamar para ningún programa y te quedarás sin trabajo. ¡Tu negocio es seguir hablando como negro!" (López, La radio 393). Jameelad Muhammad recuerda que "the language of Afro-Mexicans is sometimes said to be "unintelligible Spanish"' (175). Al describir las actuaciones de una comparsa carnavalesca afrouruguaya, Plácido afirma que "son negros semi bozalones, [...] no podrían superar [...] las dificultades que les crea la vocalización del castellano usual" (109). El historiador afroecuatoriano Estupiñán Tello describe los caseríos de negros en el interior de la provincia de Esmeraldas, que habían permanecido aislados hasta hace unas décadas, cuando se llevó a cabo la construcción del ferrocarril entre Ibarra y San Lorenzo: "los negros vivían semidesnudos y hablaban su propio dialecto [...]" (45-48).

Estos ejemplos son representativos de las actitudes negativas hacia el habla de los africanos y afrodescendientes, que prevalecen en España e Hispanoamérica desde los inicios del siglo xvi. Según la opinión popular, en varios momentos históricos, los negros son incapaces de hablar correctamente el español; los estereotipos racistas se encuentran

Revista Iberoamericana, Vol. LXXX, Núms. 248-249, Julio-Diciembre 2014, 865-882 
en la literatura, la música popular, los chistes cotidianos y aun en los planteamientos pedagógicos. Por lo tanto, es casi inconcebible que la opinión pública contemple con seriedad el español hablado en una nación de población enteramente negra, Guinea Ecuatorial. Los conceptos racistas sobre la capacidad lingüística y cultural de los negros representan impedimentos sicológicos que moldeaban la visión del habla guineana que se iba formando dentro del país y en el exterior.

\section{LA LLEGADA DE LA LENGUA ESPAÑola AL ÁFricA ECUATORIAL}

Como es bien sabido, la isla de Fernando Poo fue descubierta por un navegante portugués del mismo nombre entre los años 1469 y 1471, y fue ocupada posteriormente por los portugueses. Fernando Poo pasó a manos españolas en 1778 como resultado de los tratados de San Ildefonso y El Pardo, por medio de los cuales España le cedía a Portugal un segmento del Brasil a cambio de Fernando Poo, Annobón y un territorio vagamente definido en el continente africano. La ocupación española efectiva no comenzó hasta mucho después; entre tanto los ingleses obtuvieron permiso para utilizar la isla de Fernando Poo como sede de un tribunal mixto antiesclavista en el siglo XIX. Los españoles comenzaron a asentarse en Fernando Poo a partir de 1858 y la colonización avanzó a pasos agigantados en comparación con los demás territorios africanos y americanos. Después de poco tiempo se formó una aristocracia de plantadores de cacao, que luego se convirtió en principal sostén económico de la colonia. En Río Muni, la colonización española fue aun más tardía, puesto que fue necesario ajustar varias reivindicaciones territoriales con Francia, cuya última resolución se retrasó hasta 1900. A partir de esta fecha, España comenzó la colonización del territorio continental, pero los asentamientos se limitaban a una estrecha franja de la costa, dejando sin explorar todo el interior de Río Muni. Sólo después de 1923 fue llevada a cabo la exploración del interior del territorio continental. La autonomía territorial de la Guinea Española ocurrió en 1964 y en 1968 la República de Guinea Ecuatorial vio la luz como nación independiente. Los primeros once años de independencia fueron manchados por un régimen político que aisló a la nación de los países vecinos, y rebajó vertiginosamente el nivel de vida del pueblo guineano. Después de 1979, cuando fue derrocado el régimen dictatorial, el gobierno ecuatoguineano ha mantenido relaciones normales con el resto del mundo. En 1984, Guinea Ecuatorial se adjuntó a la zona monetaria centroafricana de países francófonos, y como consecuencia la lengua francesa se enseña en las escuelas guineanas y ha aumentado la cantidad de africanos francoparlantes llegados de los países vecinos. A pesar de la presencia del francés y del omnipresente inglés pidgin (conocido como pichinglis o simplemente pichi), el español mantiene su vitalidad como lengua nacional ecuatoguineana y aun cuanto los guineanos empleen lenguas vernaculares entre sí, reconocen que el español les brinda una identidad destacada entre las demás naciones africanas.

Revista Iberoamericana, Vol. LXXX, Núms. 248-249, Julio-Diciembre 2014, 865-882 
Cuando llegaron los primeros exploradores españoles a su nueva colonial africana hacia mediados del siglo XIx, llevaban consigo las experiencias de la esclavitud y el peonaje de las razas subyugadas, es decir, una visión de los pueblos colonizados (todos de razas extra-europeas) como naturalmente inferiores a las civilizaciones europeas. En España, los negros habían sido esclavos y luego obreros y artesanos marginados, y en Hispanoamérica todavía existía la esclavitud negra, que no fue abolida hasta la segunda mitad del siglo xIx. Como consecuencia, las primeras impresiones trasmitidas a España de los pueblos guineanos tenían un carácter netamente paternalista, y sentaban las bases para los comentarios posteriores sobre la adquisición de la lengua española por parte de los súbditos africanos. Un cubano desterrado a Fernando Poo por su oposición al régimen colonial español declaró de los españoles que había visto en África: "cuántas veces los he oído esclamar mirando las tribus salvages: ‘qué lástima que esos negros no sean esclavos!"” (Balmaseda, 135). Aunque esta actitud no fuera compartida conscientemente por todos los colonos europeos en la Guinea Española, casi todos los residentes extranjeros mantenían un sentimiento de superioridad que nublaba su reconocimiento de las verdaderas culturas africanas. A continuación se presentan algunas de las observaciones contenidas en los tratados descriptivos producidos en el primer siglo de la empresa colonial en la Guinea Española.

Uno de los primeros exploradores españoles, De los Ríos, inicia el despliegue de descripciones condescendientes y repugnantes de los pueblos guineanos, cuando describe a los bubis como "sumamente estúpidos y por lo general tímidos" (Moros y Morellón y de los Ríos 55). Para Usera y Alarcón los bubis son "algo flojos para el trabajo pero no del todo indolentes" (Memoria 13) y el autor reconoce "su carácter dulce y nada feroz" (25). Navarro considera que los bubis tienen "una constitución robusta y perfecta [...] la actividad de su vida los hace fuertes y vigorosos" (76), aunque de su lengua, dice que "no es más que un conjunto de sonidos acentuados de un modo particular" (91). Los annoboneses son "perezosos e indolentes". España debe aspirar a "la gloria de haber sacado de las tinieblas de la idolatría a una población inmensa" (126), una población "tan impresionable y de raciocinio poco desarrollado" (100). Guillemar de Aragón describe la ciudad de Clarence (después llamada Santa Isabel y hoy Malabo) de esta forma: "Es la civilización en un recinto en medio del estado salvaje; es la cuarta fase de la humanidad en medio de la primera" (63). Usera y Alarcón habla del "idiotismo e ignorancia" (Observaciones 10) de los habitantes de Annobón. Martínezy Sanz describe la actitud poco amistosa de los negros en Santa Isabel, y comenta que "no se conoce ni el idioma español, ni la religión de España, ni su moneda, ni sus costumbres" (58). Para este autor, son "la misma haraganería" y "no tienen más necesidades que la de comer" (13) y son "naturalmente tímidos y sumisos" (18). Folch y Torres dice de los bubis que "los excesos en la bebida y las pésimas condiciones higiénicas en que viven [...]

Revista Iberoamericana, Vol. LXXX, Núms. 248-249, Julio-Diciembre 2014, 865-882 ISSN 0034-9631 (Impreso) 
han hecho degenerar visiblemente la raza" (8); los annoboneses son "poco amigos al trabajo" (46). Los pamués, según este viajero, "son antropófagos y no se contentan con matar a sus semejantes para comerlos, sinó que devoran los cadáveres y aún compran los muertos de otras tribus" (59). Sorela habla de la "barbarie" (20) en que todavía se encuentran los nativos de Fernando Poo. Janikowski se refiere a los fernandinos como "caballeros de color" (71) y dice que "representan una casta que es verdadero azote en todas las costas africanas: son muy inferiores a los negros salvajes, incluso los bubis". De éstos últimos el autor dice que "en el interior de sus viviendas hay el mismo desorden, los perros y los cerdos se encargan de limpiar toda clase de inmundicias"(202). Osorio lamenta los "cerebros poco aptos para discurrir sobre ideas abstractas" (318) de los indígenas guineanos. Baumann describe el país como "poblado de gentes muy salvajes, y mal dispuestas contra el hombre blanco" (361). Labra y Cadrana nos dice que los annoboneses son "muy activos y belicosos, devotos del fetichismo" (25). Otro observador cubano, Valdés Infante describe a la raza negra de Guinea Ecuatorial como "muy degradada, refractaria a la civilización y no torpe en medio de su rudeza primitiva" (62). Muñoz y Gaviria describe a los annoboneses como "espectros ambulantes" (219) y a los bubis como "la raza de la creación "as ociosa y perezosa que existe en el mundo" (166); Arambilet se refería lúgubremente al "cuadro tristísimo del valer efectivo de las posesiones españolas en el África occidental" (12) y al referirse a la faja continental de Río Muní habla de una tierra "ocupada por seres que figuran en la parte más inferior de la especie humana" (21-22). De los bubis, dice el autor que "de todas las tribus negras del golfo de Guinea constituyen la más apática é indolente" y de los fang/pamué "sin ser tan trabajadores é inteligentes como los krumanes, están muy por encima de los bubis" (26). Ferrer Piera describe a varios personajes guineanos como esperpentos:

[...] una camisa de algodón, sucia toda ella, y rota en su mayor parte, intentaba cubrir su tronco hasta la cintura; la hoja de parra de nuestro padre Adán, se hallaba sustituida por una bolsa de tejidas fibras vegetales, y unos brazaletes de moneda en los brazos, muñecas y tobillos, completaban la indumentaria del jefe de Dio Corixo. (109)

Admite que los bubis educados por los misioneros "hablan el castellano con relativa perfección", lo cual considera un logro brillante ya que "son seres sacados de la vida salvaje, sin que haya transcurrido entre ellos ninguna generación intelectual que por ley de herencia haya podido comunicar á sus cerebros la función intelectiva" (106). Dos Oficiales del Ejército dicen que "los bubis viven en estado salvaje" (6), los annoboneses son "de carácter dulce éinofensivo"(15),y "el negro es por esencia holgazán, desconfiado y apático" (28). López Vilches admite que era generalizada la opinión de que el bubi “era un ser raquítico, holgazán é inútil" (30), aunque reconoce la fuerza de su resistencia a la colonización y recomienda que hay que "civilizarle, haciéndole participar de nuestra vida" (31). Espinosa de los Monteros aun cuando reconoce las características positivas

Revista Iberoamericana, Vol. LXXX, Núms. 248-249, Julio-Diciembre 2014, 865-882 
de los bubi y los fang/pamué, no deja de describir a los bengas como "infecundos por su amora al aocohol y a la caza" y a sus mujeres como "meretrices lúbricas" (54). De Annobón habla de sus "incultos habitantes", aunque "todos hablan el español" (81). Barrera habla de los negros "sin idea de lo que representa la palabra deber" (16); los annoboneses "hablan en casi su totalidad el español pero es la gente más miserable y menos trabajadora de nuestros territorios" (32); los pamué "tienen malos instintos y son desobedientes" (34). Muguerza Saenz desconoce por completo los derechos de los negros guineanos al observar que "aquellos salvajes creerán que les tenemos miedo y nos menospreciarán. Hay, pues, que tomar rumos distintos é imponerse por la fuerza obligandoá trabajará todos aquellos nuevos subditos"(38). De igual manera se pronuncia Gregorio Granados: "Esta falta de reprensión aumenta la audacia de aquellos salvajes, cuyo epílogo vienen á ser esas escenas de matanzas, de robos y de pillajes [...]" (18-19) Fue muy distinto el punto de vista del explorador Iradier, quien admitió irónicamente que "pasamos por liliputienses y pobres á los ojos de los indígenas" (93). Iradier reproduce el habla pidginizada de algunos habitantes guineanos, por ejemplo " Mi saber toro y hasé como dormío y marcha como culebra á uno árbol grande que tú puede mirá, Mí mira toro noche, mí no mira nada malo para ti" (África 1:179). López Perea ofrece una descripción poco halagadora de la gente de Annobón: "Sus habitaciones carecen en absoluto de toda higiene y el emplazamiento de la población es detestable [...] son ya de por sí estos indígenas refractarios á la limpieza y al aseo [...]" (73). Saavedra y Magdalena dice que los bubis "tienen poco amor al trabajo, que sólo se decidan a la caza, la pesca, el tabaco, el alcohol y la mujer" (93). Algunas poblaciones continentales son "viciosas, falaces, traidoras y rateriles" (146). Al hablar de la población benga de Corisco, afirma que "Más civilizados, su permanencia en el Continente, en plena convivencia con el salvaje pamue, se va haciendo cada vez más penosa" (184-85). Los annoboneses son "de carácter tranquilo, entusiastas por la bebida y la holganza [...]" (201); tienen "una semicultura que de momento hace formar buen concepto de ellos; mas, después de esa impresión engañosa, al ver su amor al ocio, su inclinación al alcohol, su miseria, supersticiones y vicios, no se halla sistema ni predicación para redimirlos" (202). Arija también piensa que los bengas "aunque ladinos y marrulleros, siempre fueron los más adictos e incondicionales a la causa española [...] conocen perfectamente el español" (62). Los annoboneses "conocen bastante bien el idioma español" y "son bastante espavilados de inteligencia pero muy sucios, borrachines y haraganes" (58). Bravo Carbonel afirma que los fernandinos insisten en diferenciarse de los bubis, pero "no se distancian de aquellos salvajes más que en su aspecto más distinguido y por un barmiz superficial de educación, que es pedante por ser afectada y extremosa" (43-44). Los fernandinos "abandonan muchas veces la administración de sus bienes, ignoran los principios de economía y sólo cuidan -chiquillos, adultos y ancianos-, si el dinero les falta, de procurárselo á toda costa y en cualquier forma, caminando á la ruina" (45). $\mathrm{El}$ autor ofrece el perverso comentario que "No es difícil conseguir los favores de sus

Revista Iberoamericana, Vol. LXXX, Núms. 248-249, Julio-Diciembre 2014, 865-882 ISSN 0034-9631 (Impreso) 
esposas [...] fijando de antemano el precio del favor con el marido" (46). Los bubis son "débiles y tímidos" (49), y el bubi "apenas hace nada útil" (56) y es "alcoholizado, imbécil y cobarde" (70). Los annoboneses "parecen un poco más civilizados que los demás negros, pero son muy sucios y viven en hacinamiento con cerdos y gallinas;" son "muy aficionados á las bebidas alcohólicas y poco afectos al trabajo" (68). Los "Batas" del continente "representan la parte miserable de las razas salvajes. Son tímidos heridos por la degeneración física y moral. Débiles y humildes porque conocen su escaso valimiento, tienen muy arraigados vicios de rateros y borrachos y vagos" (70-71). Los pamues sufren de una "falta de delicadeza, de dignidad, de pundonor, de caridad, de solidaridad, que son derivados de los fenómenos intelectuales y de los morales [...]" (90) Lucas de Barres (7) describe a los bubis como "raquíticos, endebles, de pequeña estatura, desprovistos de toda energía física, constituyendo una población degenerada [...]" Los annoboneses viven en "chozas miserables y sucias" (22), aunque todos hablan español, y los bujeba son "muy astutos y embaucadores, promovedores de disturbios con las indígenas del litoral y del interior" (87). Nosti Nava dice que los bubi son el grupo "más atrasado [...] protestando con su indiferencia y aislamiento de los beneficios de una cultura cristiana y de una civilización que los aleja de su vivir primitivo". Álvarez, al describir el pueblo guineano recién colonizado por España, habla de "ese pueblo [que] lleva arrastrando los sedimentos seculares de un estado propio de la más ínfima categoría humana y los complejos de inferioridad congénita que se han ido fortaleciendo durante cientos de años de esclavitud material y de ignorancia racial" (12).

\section{Primeros COMENTARIOS SOBRE EL ESPAÑOL HABLADO POR GUINEANOS}

Debido a la llegada relativamente tardía de colonos europeos a la Guinea Española, es lógico que la lengua española no haya sido adquirida completamente por los guineanos durante las primeras décadas de la colonia, aunque desde épocas muy tempranas existen testimonios de africanos que hablaban el español con soltura. De hecho, ya Moros y Morellón observaba que los annoboneses "hablan el portugués y español lo bastante para hacerse entender en las relaciones que con ellos pudieran entablarse" (27) aunque se equivoca al clasificar el dialecto criollo ( $f a$ d'ambú) como "una jerga del M'bundu que se habla en los vecinos reinos de Loango y Congo". Dadas las actitudes racistas de los europeos hacia los africanos, muchas de las observaciones sobre los primeros brotes de la lengua española entre la población guineana hacían hincapié en la incapacidad del africano de hablar correctamente el español, como si esto hubiera sido un acto voluntario o bien un indicio de debilidad mental. Bravo Carbonel dice de los pocos fernandinos que saben hablar español "aunque uno que hable castellano tenga interés vital en que le entiendan, encuentra siempre invencibles dificultades, haciéndose comprender al cabo, claro es, pero con circunloquios y rodeos y vacilaciones" (47). Los annoboneses,

Revista Iberoamericana, Vol. LXXX, Núms. 248-249, Julio-Diciembre 2014, 865-882 
en cambio, "conocen y emplean el idioma español", pronunciando la /r/ final como /1/: señol, favol (68). De Madrid tenemos la siguiente narración:

Vayamos a la relación del indígena con esta otra autoridad que es el maestro. Si éste es misionero, aprende malogradamente el castellano. Sabe decir "buenos días" cuando es por la noche y "buenas tardes" cuando es por la mañana. No sabe apenas el castellano para poderlo hablar [...] si van a la escuela oficial, aprenden un castellano correcto y enrevesado, y saben escribir con bastante claridad. (114-15)

Y también: "El castellano de los indígenas es por regla general el mismo que puede balbucir un niño de tres años. No sabe lo que es conjugar un verbo ni analizar una frase cualquiera en castellano" (145). El tenor de estos comentarios constituye un hilo que atraviesa la trayectoria lingüística guineana desde su inicio, dejando huellas que aún hoy no han sido totalmente extirpadas.

El pichinglis, lengua vernacular de los fernandinos y de la mayoría de los residentes de Malabo, también recibe críticas injustas. El pidgin-English es "bastardeado, empobrecido, y sin la elegante pronunciación de ese idioma" (Bravo Carbonel 46). Es "pernicioso influjo del que vive el país", y sufre de "la carencia de lógica en su sintaxis realmente disparatada y la pobreza de su léxico" (Castillo Barril, La influencia 52). O bien: "Esta jerga tan extendida por toda la costa occidental de África [...] constituye el esperanto de los negros, es en nuestra colonia el mayor enemigo de la expansión del castellano, porque suple las funciones de lengua intertribal que debiera llenar éste" (González Echegaray, "Notas" 107). Coll habla de la "perniciosa semilla" (54) pero se congratula por los excelentes resultados que dio la enseñanza obligatoria de la lengua española en las misiones católicas.

\section{Estudios CIENTIFICOS SOBRE EL ESPAÑOL GUINEANO}

A partir de la segunda mitad del siglo xx, y en medio del racismo todavía vigente en España e Hispanoamérica, salen los primeros trabajos científicos dedicados al español hablado por ecuatoguineanos. González Echegaray ofrece un breve perfil de la situación vigente en la Guinea Española hacia mediados del siglo xx; observa que "la progresiva hispanización [...] precisamente por sus características de rapidez e intensidad, no ha permitido la formación de un dialecto criollo, ya que tales productos suelen provenir de una larga convivencia y fermentación del idioma colonizador y del nativo" "Notas" 106). González Echegaray demostró una curiosidad científica sorprendentemente libre de lastre racista al afirmar que "[...] el castellano, puesto en boca de los negros, constituye una especial modalidad muy interesante y digna de estudio, especialmente en lo que afecta a la fonética y a la sintaxis" (106). Según González Echegaray, “aquí se ha extendido el castellano, sin haber hecho desaparecer a las lenguas vernáculas y

Revista Iberoamericana, Vol. LXXX, Núms. 248-249, Julio-Diciembre 2014, 865-882 ISSN 0034-9631 (Impreso) 
sin que se haya producido corrupción o adulteración fundamental en éstas o en aquél $[\ldots]$ ha experimentado la lengua española una serie de transformaciones y adiciones superficiales, de las más diversas procedencias" (Estudios 57). Castillo Barril ofrece comentarios sobre el español hablado por la población africana de Guinea Ecuatorial, pero se concentraba en aspectos generales ("El español”, La influencia). Reconoce el estatus del español como segunda lengua entre la población y la dificultad de castellanizar un pueblo que cuenta con una amplia gama de lenguas indígenas para la comunicación cotidiana. Este autor reconoce que el español hablado como lengua nativa nunca llegó a formar un dialecto distinto en Guinea, pero afirma que cada comunidad de habla indígena aporta sus propios rasgos al aprender el castellano, y describe las variedades del español habladas por las etnias guineanas.

Después de estos trabajos tempranos, intervino un lapso de casi dos décadas antes de la publicación de los primeros estudios del español guineano realizados por lingüistas profesionales. Granda ("Perfil") da cuenta de la diversidad lingüística de Guinea Ecuatorial, describiendo las características y los dominios de uso de las principales lenguas del país, entre ellas el español. Este lingüista atribuye la resistencia de la /s/ final de sílaba en el español hablado por guineanos de la etnia fang, así como la poca neutralización de /1/ y /r/ implosivas, a la estructura silábica del fang, que frente a otros idiomas bantúes permite una amplia gama de consonantes en la coda silábica ("Fenómenos"). A la misma vez atribuye a la interferencia del fang la neutralización de /r/-/rr/ y la realización de la /d/ intervocálica como [r]. Granda continuó su minucioso estudio del español ecuatoguineano en una larga serie de artículos, la mayoría de los cuales están recopilados por el autor (Estudios, Lingüística, El español en tres mundos, Español de América); en su totalidad constituyen el corpus de investigaciones del español guineano más extenso y diverso. Casi al mismo tiempo salieron los primeros trabajos nuestros (Lipski, "The Spanish of Malabo", "The Spanish of Equatorial Guinea", "A test", "Fonética"), después actualizados en Lipski ("The Spanish" 2000, "The Spanish" 2004, "El español" 2008). Estas investigaciones sitúan al español guineano dentro del marco de la problemática lingüística afrohispánica, sobre todo el aporte africano al español de América. Quilis y Casado-Fresnillo ofrecen la descripción sincrónica más completa del español ecuatoguineano publicada hasta la fecha. Un disco compacto que contiene fragmentos grabados acompaña el grueso libro.

\section{HACIA UN RECONOCIMIENTO DE LOS DIALECTOS ECUATOGUINEANOS DEL ESPAÑOL}

Desde su llegada a tierras africanas ecuatoriales hace dos siglos, el español ha sido una segunda lengua para la mayoría de los guineanos, y para algunos -un número que disminuye con cada generación- una lengua completamente desconocida. Siendo una segunda lengua, primero del país colonizador y después el vehículo de comunicación oficial con el resto del mundo, es lógico resistir la idea de un dialecto del español

Revista Iberoamericana, Vol. LXXX, Núms. 248-249, Julio-Diciembre 2014, 865-882 
propio de los guineanos, en vez de una serie de aproximaciones idiolectales a la lengua europea. Así ha sido el pensamiento de algunos investigadores que han enfocado la cuestión de la lengua española en Guinea Ecuatorial, a pesar de que en otros países del mundo existen variedades "regionalizadas" a base de las lenguas de las ex potencias coloniales (pensamos en la India, Filipinas y Nigeria, donde se han formado variedades propias del inglés, así como en el francés de Senegal, la Costa de Marfil y Tahiti). Quilis y Casado-Fresnillo advierten incluso que "la estabilidad de la lengua española se ve amenazada constantemente por la influencia del francés" (34); esta advertencia sugiere que el español aún no alcanza el estatus de lengua esencialmente guineana.

Nsue Otong dice que "no existe en Guinea Ecuatorial un dialecto del español como lengua institucionalizada. Sólo existe un léxico específico del país que no ha hecho sino enriquecer la lengua española [...]" (266). Vicente Granados admite que "actualmente, muchos ecuatoguineanos se esmeran, sobre todo en Malabo, en la utilización de un correcto español" (134) aunque "Al ser una lengua artificial [...] el español guineano está ligeramente fosilizado, los errores se encuentran muy dispersos y las variantes fonéticas, léxicas y gramaticales son muy amplias [...] en pocas palabras, el español guineano corre peligro de ver reducida su área a Malabo y Bata" (135). El primer lingüista guineano, Bibang Oyee, bajo el tutelaje del distinguido investigador español Antonio Quilis, opina que "en nuestro país no existe aún un dialecto acriollado (¿el español guineano?) como tal, sino una serie de rasgos característicos" (8).

A pesar de las dudas expresadas por algunos observadores, las investigaciones más recientes revelan sin lugar a duda la existencia de una serie de rasgos lingüísticos que sólo se dan en su conjunto en el español de Guinea Ecuatorial y que se producen entre la mayoría de los guineanos. Esto se refleja en la realidad de los oídos: con los ojos cerrados cualquier hispanoparlante que conozca las variedades del español mundial puede identificar inmediatamente al nativo de Guinea Ecuatorial. Así, por ejemplo, Castillo Barril habla de "el tono de voz elevado, el timbre nasal, cierta debilitación de las consonantes de articulación dura, el seseo, una entonación ligeramente melosa, con el ritmo entrecortado y una variedad de tonos silábicos" (La influencia16). Al mismo tiempo, como consecuencia de la amplia gama de niveles de bilingüismo - con distintas lenguas autóctonas- hay más fluctuación lingüística en el español de Guinea Ecuatorial que la que tipifica las zonas hispanoparlantes monolingües. Las principales características consistentes del español ecuatoguineano -dejando al lado las imperfecciones presentes en los hablantes que no han adquirido una competencia total- son las siguientes:

(1) Articulación oclusiva de /b/, /d/, /g/. La articulación de la /d/ prevocálica a veces suena como " $\mathrm{r}$ ", por ejemplo en todo, cada, y es característica de casi todos los ecuatoguineanos.

(2) Resistencia de /s/ final de sílaba/palabra: la /s/ final de sílaba y de palabra puede perderse ocasionalmente en el español ecuatoguineano, pero nunca pasa por

Revista Iberoamericana, Vol. LXXX, Núms. 248-249, Julio-Diciembre 2014, 865-882 
una etapa de aspiración, tal como sucede en muchos dialectos peninsulares, canarios e hispanoamericanos.

(3) Seseo variable: el empleo de la consonante interdental / $\theta$ / según los patrones de las zonas peninsulares de distinción fonológica alterna con el seso para la mayoría de los ecuatoguineanos. El mismo hablante puede realizar algunas palabras con la $/ \theta /$ etimológica y en otro momento emplear la $[\mathrm{s}]$ en vez de la $[\theta]$ correspondiente; es poco frecuente el ceceo, es decir el empleo hipercorrecto de $[\theta]$ en vez de $/ \mathrm{s} /$.

(4) Neutralización de /r/-/rr/: por lo regular, no existe distinción fonológica entre la /r/ simple y la /rr/ múltiple. Es algo frecuente el uso de la variante múltiple [rr] en vez de $[r]$, proceso que a veces se refleja en la literatura, por ejemplo en Ndongo Bidyogo: ““ociosidad es madrre todos visios' (eso lo decía así, su castellano) [...] el que no 'trrabaja' no come (en su castellano) [...]" (71).

(5) Combinaciones híbridas $u$ sted + forma verbal de tú: es frecuente el empleo del pronombre usted acompañado de las formas verbales correspondientes a la segunda persona del singular ( $t u ́)$. Esta combinación no se encuentra en todos los idiolectos guineanos, pero recurre con una frecuencia suficientemente alta como para ser considerada como característica representativa del dialecto. Ya tenemos evidencia de este fenómeno en la transcripción de una carta escrita por un guineano a comienzos del siglo xx: "[...] le pido á V. el perdón para que saques mi primo en el carcel, por que Señor ya sabes V. muy bien que en el carcel no conviene de estar uno allí mucho tiempo [...]" (Bravo Carbonel 77).

(6) Distinción inconsistente ustedes-vosotros. No sólo es frecuente que el mismo hablante alterne entre ustedes y vosotros al dirigirse a la misma audiencia, sino que también pueden ocurrir discrepancias de concordancia sujeto-verbo. Es más frecuente que se combina el pronombre ustedes y una forma verbal correspondiente a vosotros (por ejemplo, ustedes teneis) pero a veces de produce el caso contrario.

(7) Uso de la preposición en con verbos de movimiento: voy en Bata; yo voy en cualquiera sitio; si un padre quiere, su hijo va en la escuela.

(8) El aspecto más distintivo del español ecuatoguineano es el empleo de tonos fonológicos en cada sílaba. Todas las lenguas nativas de Guinea Ecuatorial (a excepción del annobonés) tienen tonos fonológicos asignados individualmente a cada sílaba, de manera que es lógico que los respectivos sistemas tonales influyan sobre el español guineano. Las principales lenguas de Guinea Ecuatorial distinguen dos tonos fonológicos, alto y bajo, y cada sílaba de cada palabra conlleva un tono léxico que no varía de acuerdo al contexto en que se encuentre la palabra. Esto difiere de manera significativa de la entonación del español, donde el despliegue de tonos ocurre a lo largo de la oración entera y sirve, por ejemplo, para distinguir las afirmaciones de las interrogaciones. Considérese por ejemplo la siguiente oración, pronunciada por una mujer bubi de Malabo: entonces si eres pobre, tienes un marido al menos. En su pronunciación, cada sílaba tónica recibe un tono alto, a diferencia de lo que sucede en los dialectos del español que no están en

Revista Iberoamericana, Vol. LXXX, Núms. 248-249, Julio-Diciembre 2014, 865-882 
contacto con lenguas tonales. La gráfica uno presenta un trazado de la entonación de esta oración, donde se destacan claramente los tonos altos alternantes, con el pico de entonación sobre la sílaba tónica en cada palabra. La gráfica dos presenta la misma oración pronunciada por una mujer de Madrid, España; notamos que los picos de entonación coinciden con las sílabas postónicas como es normal en el español peninsular (Hualde 102-03), y que muchas palabras no llevan ningún pico acentual.

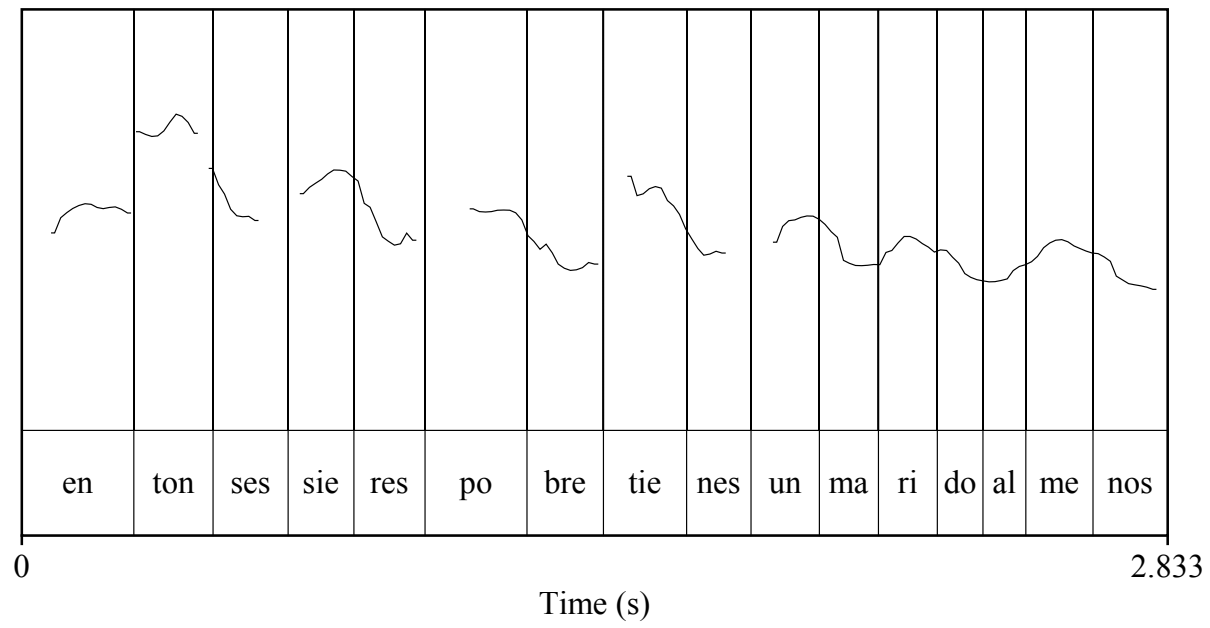

Gráfica 1: pronunciación de una mujer bubi de Guinea Ecuatorial

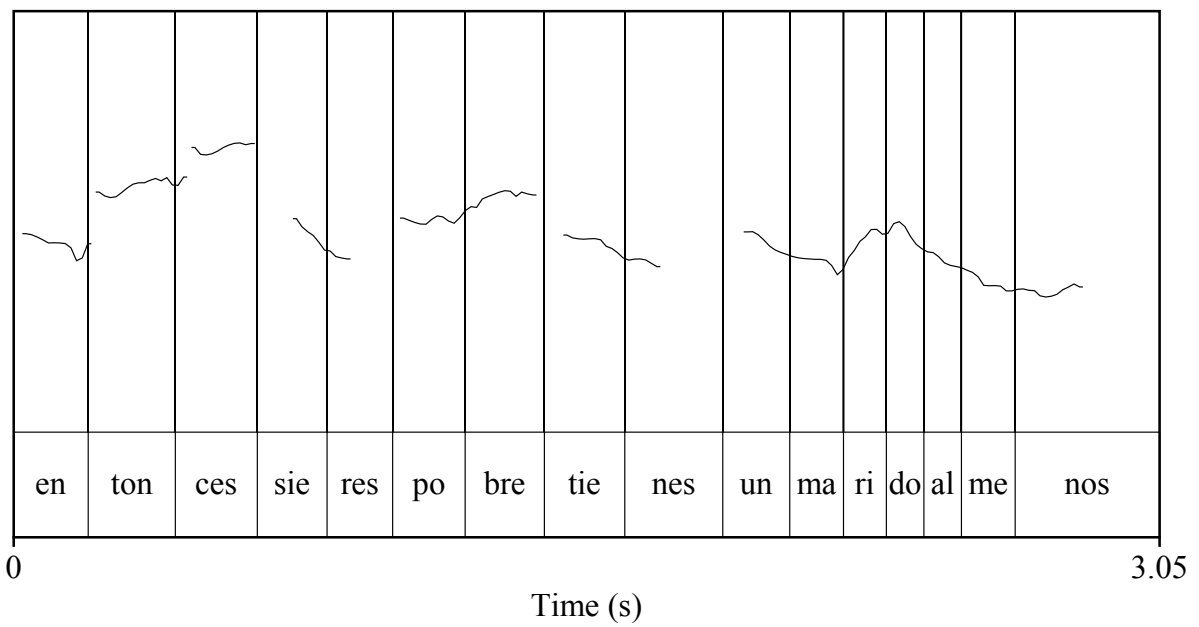

Gráfica 2: pronunciación de una mujer de Madrid, España

Revista Iberoamericana, Vol. LXXX, Núms. 248-249, Julio-Diciembre 2014, 865-882 


\section{CONCLUSIÓN: UNA REAFIRMACIÓN DEL ESPAÑOL ECUATOGUINEANO}

Debido a las circunstancias en que el español ha llegado a Guinea Ecuatorial, la variedad de lenguas originarias que lo matizan y la diversidad de entornos sociolingüísticos en que se emplea el español, el dialecto hispanoguineano combina las características prototípicas de una variedad regional (por ejemplo el andaluz, el chileno), una variedad bilingüe (Paraguay -contacto con el guaraní) y una faja de sociolectos distintos en un lugar determinado (por ejemplo la estratificación vertical del español en las zonas urbanas). El cuadro uno resume los principales rasgos del español de Guinea Ecuatorial dentro de un marco comparativo. Los datos referentes a otras zonas dialectales se explican con mayor detalle en Lipski ("El español”).

\begin{tabular}{|c|c|c|c|}
\hline RASGO GUINEANO & ¿EN EsPaña? & ¿EN AMÉrica? & ¿OTROS LUGARES? \\
\hline /b/, /d/, /g/ oclusivas & no & zonas bilingües & Filipinas, N. África \\
\hline 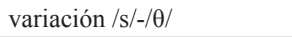 & Andalucía & no & Filipinas \\
\hline usted + verbo de $t u ́$ & no & zona quechua/aymara & $\begin{array}{l}\text { portugués de } \\
\text { Angola }\end{array}$ \\
\hline voy en Bata & no & $\begin{array}{l}\text { Río Plata (contacto con italiano); } \\
\text { Paraguay }\end{array}$ & no \\
\hline variación $U d s$-vosotros & $\begin{array}{l}\text { Andalucía } \\
\text { occ., Canarias }\end{array}$ & no & Filipinas \\
\hline neutralización /r/-/rr/ & no & zonas bilingües; afroboliviano & $\begin{array}{l}\text { Filipinas (a veces); } \\
\text { judeo-español }\end{array}$ \\
\hline $\begin{array}{l}\text { tonos individuales en cada } \\
\text { sílaba }\end{array}$ & no & $\begin{array}{l}\text { afrodominicano, S. Basilio } \\
\text { (Colombia) }\end{array}$ & no \\
\hline
\end{tabular}

\section{Cuadro 1: Ubicación dialectológica del español de Guinea Ecuatorial}

En conclusión, el reconocimiento del español ecuatoguineano se ha visto obstaculizado por una larga historia de discriminación y menosprecio de las hablas afrohispánicas, desde el siglo Xv hasta el XxI. En su perfil sociolingüístico no difiere de manera significativa del español hablado como segunda lengua en otras comunidades de habla bilingües, por ejemplo en Paraguay, la zona andina y México. El hecho de que el español ecuatoguineano se identifique inmediatamente al ser escuchado, goce de una tradición literaria polifacética y diversa, y sirva de emblema de identidad de una nación soberana, representa una prueba contundente de su estatus como legítima variedad dialectal del español.

Revista Iberoamericana, Vol. LXXX, Núms. 248-249, Julio-Diciembre 2014, 865-882 


\section{BiBLIOGRAFÍA}

Álvarez, Heriberto Ramón. "Cómo educa España en Guinea”. Los territorios españoles del Golfo de Guinea. Madrid: Revista Geográfica Española, 1950.

Arambilet, Santiago. Posesiones españolas del África occidental. Madrid: Revista General de Marina, 1903.

Arija, Julio. La Guinea Española y sus riquezas. Madrid: Espasa-Calpe, 1930.

Balmaseda, Francisco Javier. Los confinados a Fernando Poo e impresiones de un viage a Guinea. Nueva York: Imp. de la Revolución, 1869.

Barrera, Ángel. Lo que son y lo que deben ser las posesiones españolas del Golfo de Guinea. Madrid: Eduardo Arias, 1907.

Baumann, Oscar. "La isla de Fernando Poo". Boletín de la Sociedad Geográfica de Madrid 22 (1887): 359-65.

Bibang Oyee, Julián-B. El español guineano: interferencias, guineanismo. Malabo: n.p., 2002.

Bravo Carbonel, J. Fernando Poo y el Muni: sus misterios y riquezas. Madrid: Alrededor del Mundo, 1917.

Castillo Barril, Manuel. “El español en la Guinea Ecuatorial”. Español Actual3(1964): 8-9. La influencia de las lenguas nativas en el español de la Guinea Ecuatorial. Madrid: Consejo Superior de Investigaciones Científicas, 1966.

"La influencia de las lenguas nativas en el español de Guinea". Archivo de Estudios Africanos 20 (1969): 46-71.

Coll,Armengol. Segunda memoria de las misiones de Fernando Poo y sus dependencias. Madrid: San Francisco de Sales, 1899.

Dos Oficiales del Ejército. Posesiones españolas en el África occidental. Madrid: Imprenta y Litografía del Depósito de la Guerra, 1900.

Espinosa de los Monteros, Ramos. España en África. Madrid: R. Velasco, 1903.

Estupiñán Tello, Julio. El negro en Esmeraldas. Quito: Casa de la Cultura Ecuatoriana, 1967.

Ferrer Piera, P. Fernando Póo y sus dependencias. Barcelona: A. López Robert, 1900. Folch y Torres, José. África española. Barcelona: Antonio J. Bastinos, 1911.

González Echegaray, Carlos. "Notas sobre el español en África". Revista de Filología Española 35 (1951): 106-18.

Estudios guineos, t. 1: filología. Madrid: Instituto de Estudios Africanos, 1959.

Granados, Gregorio. Páginas sueltas sobre la Guinea Española. Barcelona: Sucesores de Vda. de J. Miguel, 1912.

Granados, Vicente. "Guinea: del 'falar guinéu' al español ecuatoguineano". Epos 2 (1986): 125-37.

Granda, Germán de. El español en tres mundos: retenciones y contactos lingüisticos en América y África. Valladolid: U de Valladolid, 1991.

Revista Iberoamericana, Vol. LXXX, Núms. 248-249, Julio-Diciembre 2014, 865-882 
Español de América, español de África y hablas criollas hispánicas. Madrid: Gredos, 1994.

Estudios de lingüística afro-románica. Valladolid: U de Valladolid, 1985.

"Fenómenos de interferencia fonética del fang sobre el español de Guinea Ecuatorial: consonantismo”. Anuario de Lingüística Hispánica 1 (1984): 95-114. Lingüística e historia: temas afro-hispánicos. Valladolid: U de Valladolid, 1988. "Perfil lingüístico de Guinea Ecuatorial". Homenaje a Luis Flórez. Bogotá: Instituto Caro y Cuervo, 1984. 119-95.

Guillemar de Aragón, Adolfo. Opúsculo sobre la colonización de Fernando Póo y revista de los principales establecimientos europeos en la costa occidental de Africa. Madrid: Imprenta Nacional, 1852.

Hassaurek, Frederick. Four Years among Spanish-Americans. Nueva York: Hurd and Houghton, 1868.

Hualde, José Ignacio. "Intonation in Spanish and the other Ibero-Romance Languages: Overview and Status Quaestionis". Romance Phonology and Variation: Selected Papers from the 30th Linguistic Symposium on Romance Languages, Caroline Wiltshire y Joaquim Camps, eds. Amsterdam y Filadelfia: John Benjamins, 2002. 103-15.

Iradier, Manuel. África: viajes y trabajos de la Asociación Euskera La Exploradora. Tomo I. Bilbao: Andrés P.-Cardenal, 1901.

África: viajes y trabajos de la Asociación Euskera La Exploradora. Tomo II. Bilbao: Imp. y Enc. de Andrés P.-Cardenal, 1901.

Janikowski, L. "La isla de Fernando Poo: su estado actual y sus habitantes". Boletín de la Sociedad Geográfica de Madrid 22 (1887): 67-77, 201-11.

Labra y Cadrana, Rafael María de. Las colonias españolas del Golfo de Guinea. Madrid: Alfredo Alonso, 1897.

Laviña, Javier, ed. Doctrina para negros: explicación de la doctrina cristiana acomodada a la capacidad de los negros bozales, de Nicolás Duque de Estrada. Barcelona: Sendai, 1989.

Lipski, John. A History of Afro-Hispanic Language. Cambridge: Cambridge UP, 2005. "A Test Case of the Afro-Hispanic Connection: Final /s/ in Equatorial Guinea". Lingua 68 (1986): 357-70.

"El español de Guinea Ecuatorial en el contexto del español mundial". La situación actual del español en África. Gloria Nistal Rosique y Guillermo Pié Jahn, eds. Madrid: Casa de África/SIAL, 2008. 79-117.

El español de Malabo: procesos fonéticos/fonológicos e implicaciones dialectológicas. Madrid/Malabo: Centro Cultural Hispano-Guineano, 1990. "Fonética y fonología del español guineano: implicaciones para la dialectología hispánica”. Africa 2000 Año II, Epoca II, núm. 1 (1987): 9-17.

Revista Iberoamericana, Vol. LXXX, Núms. 248-249, Julio-Diciembre 2014, 865-882 
"The Spanish of Equatorial Guinea." Arizona Journal of Hispanic Cultural Studies 8 (2004): 115-130.

"The Spanish of Equatorial Guinea: Research on la hispanidad's Best-kept Secret". Afro-Hispanic Review 19 (2000): 11-38.

The Spanish of Equatorial Guinea. Tubinga: Max Niemeyer, 1985.

"The Spanish of Malabo, Equatorial Guinea and its Significance for Afro-Hispanic Studies". Hispanic Linguistics 1 (1984): 69-96.

López, Oscar. La radio en Cuba. La Habana: Letras Cubanas, 1981.

López Perea, Enrique. Las posesiones españolas del Golfo de Guinea. San Fernando: n. p., 1906.

López Vilches, Eladio. Fernando Póo y la Guinea Española. Madrid: Depósito de la Guerra, 1901.

Lucas de Barres, Alfonso de. Posesiones españolas del Golfo de Guinea. México: s.n., 1918.

Madrid, Francisco. La Guinea incógnita (vergüenza y escándalo colonial). Madrid: Ed. España, 1933.

Martínez y Sanz, Miguel. Breves apuntes sobre la isla de Fernando Póo. Madrid: Higinio Reneses, 1856.

Moros y Morellón, José y Juan Miguel de los Ríos. Memorias sobre las islas africanas de España, Fernando Póo y Annobón. Madrid: Compañía Tipográfica, 1844.

Muguerza Saenz, Simeón. Fernando Póo: su actual situación agrícola y comercial y su porvenir. Barcelona: Tip. Vda. D. Casanovas, 1907.

Muhammad, Jameelah. "Mexico". No longer invisible: Afro-Latin Americans Today. Londres: Minority Rights Publications, 1995. 163-80.

Muñoz y Gaviria, José (Vizconde de San Javier). Tres años en Fernando Póo: viaje a Africa. Madrid: Urbano Manini, 1899.

Navarro, Joaquín. Apuntes sobre el estado de la costaoccidental de Áfricayprincipalmente de las posesiones españolas en el Golfo de Guinea. Madrid: Imprenta Nacional, 1859.

Ndongo Bidyogo, Donato. Las tinieblas de tu memoria negra. Madrid: Fundamentos, 1987.

Nosti Nava, J. Notas geográficas y económicas sobre los territorios españoles del Golfo de Guinea. Madrid: Espasa-Calpe, 1942.

Nsue Otong, Carlos. "Guineanismos o español de Guinea Ecuatorial". Muntu 4-5 (1986): 265-68.

Osorio, Amado. "Condiciones de colonización que ofrecen los territorios españoles del Golfo de Guinea". Boletín de la Sociedad Geográfica de Madrid 22 (1887):314-32.

Pichardo, Esteban. Diccionario provincial casi razonado de voces cubanas. La Habana: M. Soler, 1849.

Plácido, Antonio. Carnaval: evocación de Montevideo en la historia y la tradición. Montevideo: Letras, 1966.

Revista Iberoamericana, Vol. LXXX, Núms. 248-249, Julio-Diciembre 2014, 865-882 
Quevedo, Francisco de. Obras completas, T. 1. Prosa. Madrid: Aguilar, 1988.

Quilis, Antonio y Celia Casado-Fresnillo. La lengua española en Guinea Ecuatorial. Madrid: U Nacional de Educación a Distancia, 1995.

Saavedra y Magdalena, Diego. España en el África occidental (Río de Oro y Guinea). Madrid: Artística Española, 1910.

Sorela, Lieutenant. Les possessions espagnoles du Golfe de Guinée. París: A. Lahure, 1884.

Usera y Alarcón, Jerónimo. Memoria de la isla de Fernando Poo. Madrid: T. Aguado, 1848.

Observaciones al llamado Opúsculo sobre la colonización de Fernando Póo publicado por D. Adolfo de Guillemar. Madrid: Eusebio Aguado, 1852.

Valdés Infante, Emilio. Cubanos en Fernando Póo: horrores de la dominación española en 1897 a 1898. La Habana: El Fígaro, 1898. 